\title{
Medication of Production Animals - Cure of Malfunctioning Animals or Production Systems?
}

\author{
By Mariann Chrièll and Hans Henrik Dietz ${ }^{2}$
}

${ }^{1}$ Danish Dairy Board and ${ }^{2}$ Danish Institute for Food and Veterinary Research, Aarhus, Denmark.

\begin{abstract}
Chrièl M, Dietz HH: Medication of production animals - cure of malfunctioning animals or production systems? Acta vet. scand. 2003. Suppl. 98, 65-70. - Medication is used in all intensive animal productions. However, the increasing problems with resistant bacteria in all animal productions and in humans are supported by a number of reports. Special attention is given to the risk for transmitting food-borne (multi) resistant zoonotic agents to humans due to failure in antibiotic treatment resulting in lower cure rates or higher case fatality rates.

The use of medication in humans per se is capable of selecting for resistance in human pathogens. Nevertheless, the amount of used medication/antimicrobials in treatment of Danish production animals goes far beyond the amount used for human consumption. The increase in consumption has not been followed by a similarly increased mortality, e.g. illustrated by the number of rendered animals, increased use of injection medicine for veterinary treatments of diseased animals, or increased number of remarks on the carcasses from the slaughterhouses.

Medication in animal production is facing its limits and relevant economic alternatives have to be developed. The strategy for the future must concentrate on using medication only for clinically diseased animals and not as a strategic treatment of the whole herd in order to maximise growth and camouflage of suboptimal production systems and insufficient management.
\end{abstract}

\section{Introduction}

Dealing with intensive animal production systems differs from more undeveloped livestock productions among others in the composition of diseases and the lower productivity due to infectious diseases. However, the increase in productivity and the demand for additional profitability is not only achieved by improved breeding stock and herd health programmes but is also supplied by strategic use of medication i.e. mainly antibiotics. Medication is no longer regarded as a therapeutic substance but more like a necessary mean to achieve maximal growth in inferior production facilities and is considered to be a normal part of all intensive animal production systems.
The negative consequences of using antimicrobials are numerous. Antimicrobials affect the ability of early detection of exotic diseases. The epidemic of classical swine fever (CSF) in the Netherlands remained undetected for several weeks due to the liberal use of antimicrobials for symptomatic treatment of sows with abortion and undulant fever (Elbers et al. 1999). This delayed the detection of CSF and thereby enhanced the magnitude of the epidemic.

The increasing problems with resistant bacteria in all animal productions and in humans are supported by a number of reports (Anon. DANMAP 1997-2000). Special attention is given to the risk for transmitting food-borne (multi-) re- 
sistant zoonotic agents to humans due to failure in antibiotic treatment resulting in lower cure rates or higher case fatality rates.

In 1995 DANMAP, the Danish Integrated Antimicrobial Resistance Monitoring and Research Programme, was initiated. The objective of the programme was to monitor the occurrence of antimicrobial resistance among bacteria isolated from production animals, food and humans as well as the consumption of antimicrobials. The results are registered in a database and will form the scientifically based prudent use of antimicrobials - may it be growth promoters as well as for therapeutic use of antimicrobials to production animals.

Several factors are important for the route of administration, the threshold for initiating treatment and selection of animals for medication. The majority of these factors are fixed by the farmer and strongly influenced by the output profile of the species concerned. Dairy cows with daily output and an inevitable withdrawal period for the milk after treatment are medicated individually by parenteral, uterine or mammary dosing. Species having a single life production - e.g. pork, beef or poultry - are more prone to orally medication in whole groups or herds irrespective of the individual animal's health status.

Before 1995 the Danish consumption of antimicrobials was regulated only by means of legal requirements for veterinary prescription of the product. Due to a significant rise in the consumption in the beginning of the nineties the legislation was intensified and statutory herd health counselling became mandatory for farmers to initiate therapeutic medication of production animals. The legislation differs for the different species, but it was specified that prophylactic treatment should be banned and the veterinarian was only allowed to prescribe antimicrobials for animals in a well-defined incubation period and after personal or laboratory diagnosing. Furthermore, the use of growth promoters was banned by the 31st August 1999 in Denmark.

Objective, quantitative information regarding the usage patterns by animal species, antimicrobial class, potency and type of use are all essential elements in an evaluation of the antimicrobial exposure. Problems in establishing associations between the consumption of an-

$\square$ Oral $\square$ Injectable $\square$ Total therapeutic $\square$ Growth promoter

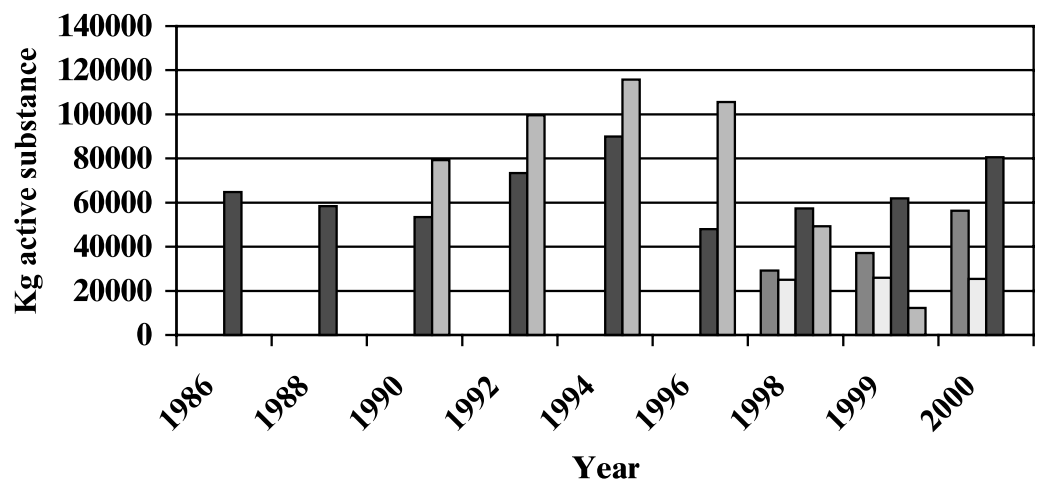

Figure 1. Usage of antimicrobials in food animals in Denmark (1986-2000) (Anon. 2000). 
$\square$ Mortality pigs $\square$ Mortality sows

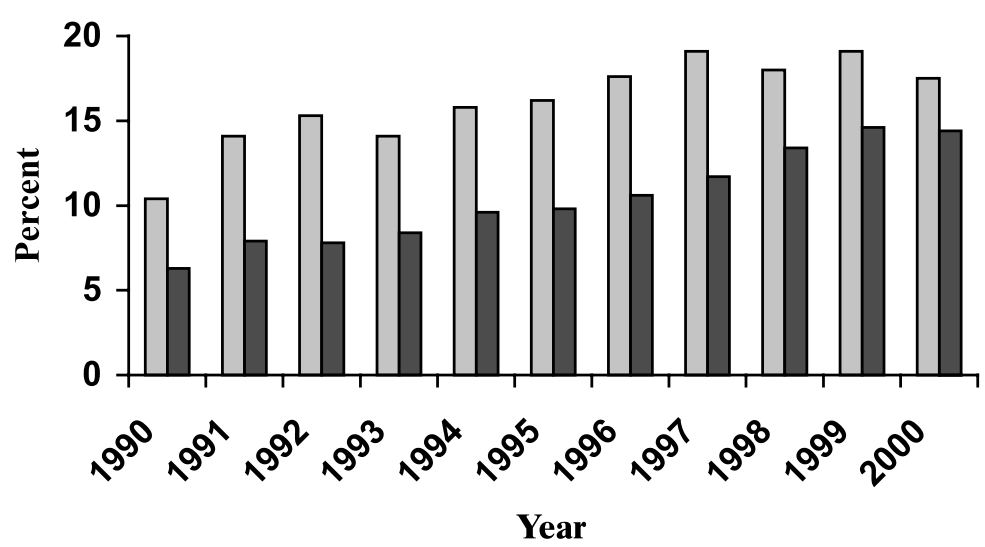

Figure 2. Mortality rate in the Danish swine production (Anon. 2001a, 2001b).

timicrobials used for production animals and the detection of resistant bacteria in humans were soon identified. Hitherto only the total consumption was registered and lack of knowledge regarding species, herd and dose was noted in order to draw conclusions.

Therefore, in May 2000 VETSTAT was initiated in Denmark. This register is based on the Central Husbandry Register (CHR) and all antimicrobial prescriptions are registered on farm level including details about the veterinary practice prescribing the antimicrobial as well as the species, age and date of treated group of animals, and diagnosis.

The use of medication in humans per se is capable of selecting for resistance in human pathogens. Nevertheless, the volume of used medication/antimicrobials in treatment of Danish production animals goes far beyond the volume used for human consumption (Anon. 2000). After banning of the use of growth promoters in Denmark an increase in the use of therapeutic medication was predicted. Nevertheless, the consumption figures for oral medi- cation from 1999 demonstrated a clear reduction to 32 tons active substance, succeeded by a $50 \%$ increase in 2000 to 50 tons whereas the use of antimicrobials for parenteral (injection, mammary and uterine) treatments have remained stable (data not shown). Decline in the consumption of antimicrobials has only been registered after implementation of new regulations banning products like the growth promoters in 1999 (Fig. 1).

The mink production is a good example as it is run in a very simple system due to a highly hierarchical and clustered structure of the whole production system and the monocyclic nature of the animal. Results from studies showed that $80 \%$ of the variation in the incidence of gastrointestinal disorders was associated with the feed producer (Rattenborg et al. 1999). However, bacteriological examination of faecal samples have demonstrated that presence of haemolytic staphylococci and haemolytic $E$. coli was neither associated with presence of clinical symptoms of diarrhoea nor with increased mortality in the same period (Vulfson et 


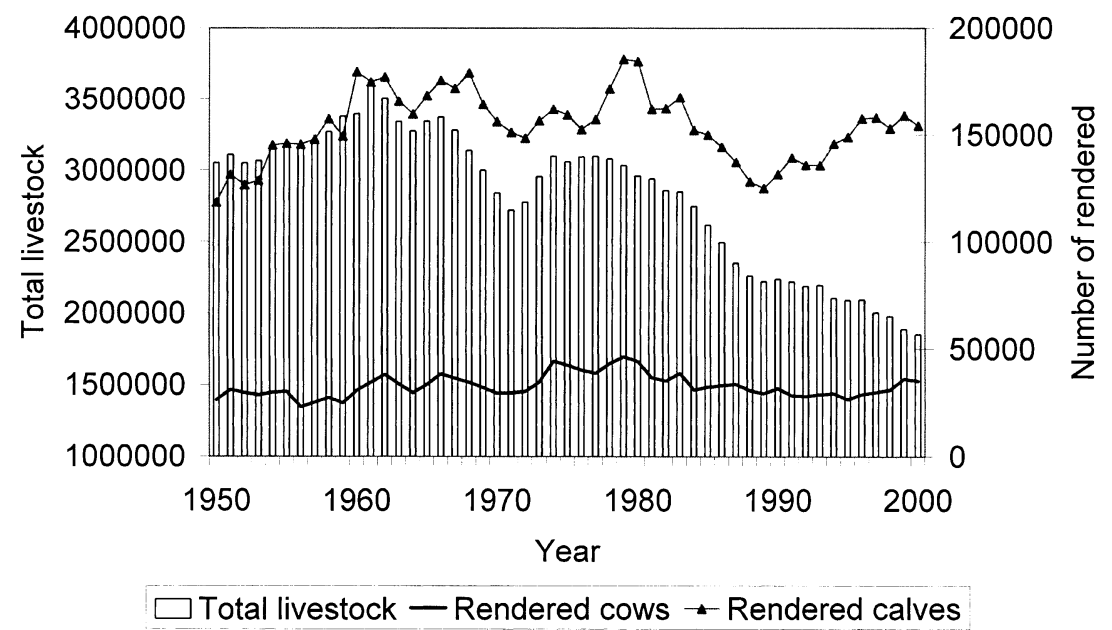

Figure 3. The total number of Danish cattle livestock and rendered cattle in the last 50 years. (Anon. 2001a, 2001b).

al. 2001). Furthermore, substantial consumption of antimicrobials was correlated to poor feed quality from one feed producer in the weaning and growth period in 1999 (Chriél \& Dietz 2000). But, in order to obtain the maximal growth rate in the weaning and growth period mink kits are fed ad libitum. Furthermore, the composition of the feed is based on test results in order to achieve the maximum growth and not taking the health of the animals sufficiently into account. Hence, the capacity of growth impairs the health of the animals. One might argue that because mink is not part of the stable-to-table chain no concerns regarding use of antimicrobials have to be taken. This approach is, however, not in accordance with the public opinion and is to be regarded as an irresponsible attitude to good farm practice. Danish recommendations are more and more focused on reducing the consumption of antimicrobials, not as a goal in itself, but rather as a tool for optimisation of production facilities and management practices.

Focus on the hazards of resistant bacteria has so far been aimed at food producing animals. Nevertheless the potential risk of spreading antimicrobial-resistant organisms as well as remnants of medicine etc. to the environment have been addressed in studies of the spread of manure and slurry (Andersen \& Hald 2001), but free range animal productions and fur production takes place in direct contact with the environment.

The usage patterns of antimicrobials for injection used for individual therapy of diseased production animals have remained constant over the last 3 years. The significant increase in consumption of oral medication has not been followed by a similarly decreased mortality, e.g. illustrated by the number of rendered animals (Fig. 2 and 3), or increased number of remarks on the carcasses from the slaughterhouses.

The increased use of antibiotics from 1999 to 2000 is predominantly for oral medication on a farm/herd basis an administration primarily used in the pig production. This type of medication results first of all in medicating healthy animals together with diseased animals. Fur- 
$\square$ Swine $\square$ Swine/cattle $\square$ Cattle

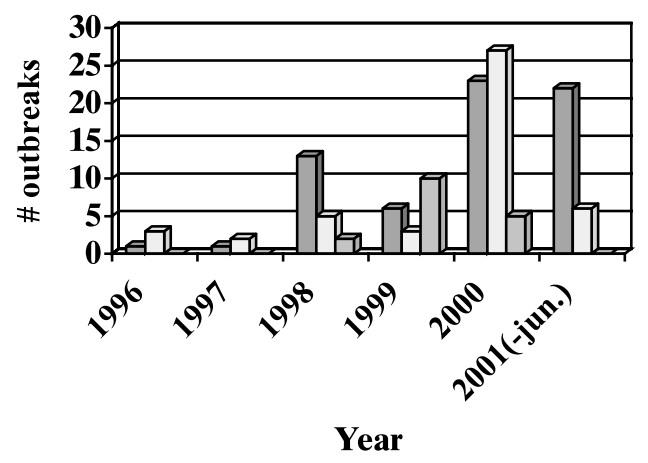

Figure 4. The annual incidence of Salmonella typhimurium DT104 in Danish production herds (Anon. 2000).

thermore, the efficiency reports of which the individual farmer is comparing his own production results are all based on the maximum achievable growth a result that often has been achieved by use of medication but not corrected for. The natural limit of body-growth has been pushed upwards during the last decades.

As an example Norway (Grave \& Rønning 2001) and Sweden (Odensvik 2001) have seen a decrease in the consumption of antimicrobials in 2000. Veterinary compliance with national guidelines on selection and use of drugs is mentioned as part of the explanation of the more prudent use of the products but also improved preventive measures. However it should be borne in mind that the agricultural structure is less intensive and with a significant lower output than the Danish animal production.

The first detection of an emerging pentadrugresistant Salmonella Typhimurium DT104 clone was done in the beginning of the 1990 in UK (Wall et al. 1994). This clone has now spread worldwide. Although no overall increase in the incidence of salmonellosis has been detected this clone accounts for more than
$35 \%$ of the cases in US (Tauxe 1999). Despite the fact that use of antimicrobials is not indicated in treatment of human salmonellosis it is often prescribed. The treatment will affect the normal intestinal flora and thereby facilitate the selection of resistant bacteria. Epidemiological studies have shown that the only significant risk factor for human DT104-outbreaks was use of antibiotics prior to the outbreak (Holmberg et al. 1984).

In 1996 the first outbreaks of DT104 were diagnosed in 4 Danish herds. All 4 pig herds were stamped out and the 3 cattle herds were closed till no DT104 bacteria were shed and hence declared free. This policy was followed till 2000 when it was replaced by special measures taken at the slaughter process due to a significant rise in the annual incidence (Fig. 4). If a similar process is involved in the outbreaks of DT104 in animal production as observed in humans, the widespread use of antimicrobials and circulation of slurry to the near-by environment may be contributing significantly to an aggravation of the problem.

Despite all the efforts taken in public as well as privately financed research activities and all the knowledge of correct management of the production animals we have still not seen substantial progress in the health and welfare of the animals. Furthermore, it seems that the increasing number of specialised veterinary and agricultural consultants have not improved the animal health considerably but only assisted in keeping up the productivity by means of medication.

Medication in animal production is facing its limits and relevant economic alternatives should be developed. The future strategy must concentrate on using medication only for clinically diseased animals and not as a strategic treatment of the whole herd in order to maximise growth and camouflage suboptimal production systems and/or insufficient management. It is in everyone's interest that effective 
antimicrobials remain available for appropriate use in animals and humans, and the veterinary profession must continue to play its important part in helping to ensure this. New guidelines can act to help to ensure that antimicrobials are used prudently and responsibly, but it is important that the individual veterinarian is aware of his/her responsibility to ensure that the principles propounded are effectively applied.

Although the economic benefits of using medicine may exceed the costs, the public opinion should not accept animal productions based on routine medication as a prerequisite for sustaining adequate welfare and profitable production.

\section{References}

Andersen JS, Hald T: Risikovurdering ved anvendelse af vandingskanoner til udspredning af gylle fortyndet med vand. (Human health risk assessment concerning the use of high volume irrigation guns for spreading manure diluted with water on agricultural fields). Miljøprojekt $\mathrm{Nr} 606$, 2001, Danish Zoonosis Centre, Danish Veterinary Laboratory.

Anonymous: DANMAP 2000 - Consumption of antimicrobial agents and occurrence of antimicrobial resistance in bacteria from food animals, food and humans in Denmark. Danish Zoonosis Centre, Danish Veterinary Laboratory, 2000.

Anonymous: Annual statistics for the Danish rendering plants 2000. Danish Veterinary and Food Administration, 2001a.

Anonymous: Statistical Yearbook 2000. Statistics Denmark, 2001b.

Elbers ARW, Stegeman A, Moser H, Ekker HM, Smak
JA, Pluimers FH: The classical swine fever epidemic 1997-1998 in the Netherlands: descriptive epidemiology. Prev.Vet.Med 1999, 42, 157-184.

Grave K, Rønning M: Nedgangen af forbruket af antibakterielle veterinærpreparater til husdyr i Norge fortsatte i år 2000. (Reduction in the consumption of veterinary antibacterial products for animals continued in 2000). Norsk Veterinærtidsskrift 2001, 113, 5: 291-297.

Holmberg SD, Osterholm MT, Senger KA, Cohen $M L$ : Drug-resistant Salmonella from animals fed antimicrobials. N Engl J Med 1984, 311, 617622.

Odensvik, $K$ : Försäljning af antibakteriella och antiprasitära läkemedel för djur 2000. (Sale of antibacterial and antiparasitary products for animals in 2000). Sv Vet Tid 2001, 53, 7: 401-404.

Rattenborg E, Chriél M, Dietz HH: Influence of farm, feed producer and season on the incidence of gastrointestinal disorder in Danish mink farms. Prev. Vet. Med. 1999, 38, 231-237.

Tauxe RV: Salmonella Enteritidis and Salmonella Typhimurium DT104: Successful Subtypes an the Modern World. In: Scheld WM, Craig WA, Hughes JM, (eds): Emerging infections Press, Washingtom, DC. 1999, pp. 32-52.

Vulfson L, Pedersen K, Chriél M, Frydendahl K, Holmen Andersen T, Madsen M, Dietz HH: Serogroups and antimicrobial susceptibility among Escherichia coli isolated from farmed mink (Mustela vison Schreiber) in Denmark. Vet. Microbiol. 2001, 79: 143-153.

Wall, $P G$, Morgan D, Lamden K, Ryan M, Griffin M, Threlfall EJ, Ward LR. Rowe B: A case control study of infection with an epidemic strain of multiresistant Salmonella typhimurium DT104 in England and Wales. Communic. Dis. Rep. 1994, 4. R130-R135.

Contribution to 11. International Conference on Production Diseases in Farm Animals, 12-16 August 2001, KVL, Frederiksberg, Denmark.

Reprints may be obtained from: M. Chriél. E-mail: mac@dfvf.dk, tel: +45 72346000. 